International Journal of Engineering \& Technology, 7 (4.33) (2018) 56-59
International Journal of Engineering \& Technology
SPC
Website: www.sciencepubco.com/index.php/IJET
Research paper

\title{
Investigating Job Satisfaction Using Exploratory Factor Analysis at ABC Factory
}

\author{
W. N. H. Wan Abdul Aziz ${ }^{1 *}$, F. Zulkipli1, M. H. Mohammad Hamzah', F. W. Azhar ${ }^{1}$, S. K. N. Abdul Rahim² \\ ${ }^{I}$ Faculty of Computer and Mathematical Sciences, Universiti Teknologi MARA, Perak Branch, Tapah Campus, Tapah Road, \\ 35400 Perak, Malaysia \\ ${ }^{2}$ Faculty of Computer and Mathematical Sciences, Universiti Teknologi MARA, Shah Alam, 40450 Selangor, Malaysia \\ *Corresponding author E-mail: wannoo124@ perak.uitm.edu.my
}

\begin{abstract}
The aim of this research is to study the workforce allocation at ABC Factory. A set of questionnaire consists of two parts, which are background of respondent and job satisfaction components were distributed among 80 employees. The statistical method exploratory factor analysis (EFA) was used to classify the components. As a result, the research revealed that there are three main components which are work environment, productivity, and organization can be classified by 25 questions.
\end{abstract}

Keywords: Exploratory Factor Analysis; Job Satisfaction; Organization; Productivity; Work Environment.

\section{Introduction}

In recent years, job satisfaction is an important factor that affects manufacturing-based industries to deliver good services to their customers. Behaviors of company representatives are the source of differentiation as compared to their competitors and will influence whether customers remain loyal or switch to other service provider. Job satisfaction related to work environment, productivity together with organization is an essential component to produce innovative product and outshine plant competitors. Employee performance at the workplace was a cause effect based on their orientation on emotion in job satisfaction. Job satisfaction is the affective orientation that an employee serves to the organization. It can be employee motivation and overall feeling that encourage employee to feel positive or negative with their jobs. Employees who are satisfied with their job tasks assigned resulting them to feel happy, having high energy and pleasurable and directly improve plant productivity. Job satisfaction may protect workers from not performing to the standard plant expectations.

The environment itself made an organization facing various challenges. Working environment can be defined as the place surrounding the employment to complete their tasks. A good working environment provided by the organization will make employees feel meaningful and tend to give an impressive working task. According to [1], employees will be more motivated throughout the day when they have a safety working environment, job security, and a good relationship between other workers. Several factors of the working environment may affect job satisfaction such as duration of working hours, structure of organization, and cooperation between workers and plant.

Productivity of product and efficiency of working is important to satisfy customer demand. Generally, factory have bottlenecks when they produce early or late delivery and it will limit the whole entire project. The cost of paying the labors will increase when the work is delayed, and schedule is prolonged to complete some productions. Otherwise, early delivery of the product force the assembly department to handle various tasks in the certain period and they need a huge store to storage the finished goods. Hence, the scheduling of productivity becomes ineffective and inefficient due to lack of productivity planning. Therefore, on time delivery based on customer requirement is important to the plant in order to minimize their production cost and maximize the profit to the company [2].

According to [3], the most popular fit in organization behaviour is person-organization. Organizational performance may cause rate of employees' turnover, workers' performance, stress and workplace social structure. Organizational issues usually influence employee and employer to implement the process of contract. Employee behavior relate to job satisfaction and organizational commitment help the workers to feeling comfortable with the culture.

This study performed two main analyses that are Descriptive Analysis and Exploratory Factor Analysis (EFA) using IBM SPSS Statistics 22 package. Descriptive Analysis is an essential for every research to describe the data into informative way, where the demography data is presented graphically in terms of percentage [45]. Regarding researchers' results, the purpose of this article is to present the result of the factor related to job satisfaction using exploratory factor analysis (EFA), coupled with development of constructed factors that demonstrate appropriate result. Next, the empirical study classified the questionnaire by each component through exploratory factor analysis method.

\section{Literature Review}

\subsection{Job Satisfaction}

According to [6], the definitions of job satisfaction are different from time to time according to current state or situation. This finding is supported by [7] who suggested that economic cycles can also affect the level of job satisfaction among workers. As we know, 
the industrial revolution happened when the industry was affected by the innovation and technological changes. These revolutions were caused by mechanical (1st revolution), steam and electrical energy used (2nd revolution), electronics and automation (3rd revolution) and currently the digitalization and robotics (4th revolution). All these industrial revolutions did not influence only the production itself, but also the labor market and the educational system as well. As a result of this, some professions had disappeared. Workers become more intense with their job.

There are certain cases where the turnover rate among workers are very high, especially in the manufacturing area. High turnover rate will give a negative impact to both parties, whether the company or the clients and also to the employee itself. Frequent staff turnover will expose the company with inexperienced workers with a doubtful loyalty and also more costly since they are needed to be trained very well. That is why job satisfaction is very important and needed among workers in order to produce a good employee who will benefits both party: the company and the clients itself. Some factors identified being the main reason of job satisfactions among workers such as productivity, work environment and organization which will be discussed later.

Job satisfaction according to [8] is a concept which is widely studied in organizational behavior research, is commonly conceptualized as an affective variable that results from an individual's job experience or simply the extent to which people like their jobs'. In [8] also proposed the job satisfaction to be explained based on the equity theory. Equity theory requires balance between the inputs and outputs of an employee. Input consists of composite of time, effort, ability and loyalty committed by the employee while output are the reward such as salary, bonuses, security and enjoyment.

In [9] on the other hand suggested that job satisfactions are defined from many perspectives such as an attitude towards work-related conditions, response to a specific job or various aspects of the job, how meaningful a job to the individual, the nature of the job itself and many more. On the other hand, job satisfaction also can be defined as an innovation process by the organization in improving the employee skills and knowledge from time to time [10].

\subsection{Factors Contributing to Job Satisfaction}

To become an employee with a high level of job satisfaction, several components need to be looked not on the employee sides only, but also the company demand, client's needs, environment situation and many more. All of these factors will be the reason of creating a very high skills and high motivated employee for the respected organization. That is why job satisfaction is very important to every employee. There are lots of factors contributing to job satisfaction based on the recent research.

In [11] suggested that the main factors to increase the level of job satisfaction is the role of the supervisor or leader of the group. Their research has shown that the better the emotional and relationship among leader and workers the higher their level of job satisfaction. The worker's welfare and wages also can increase the level of job satisfaction [12]. In their research among workers in agro-foodproducing and processing sectors, the more benefit the workers get due to their performance in job, the better the workers will become. They even have their own workers and management body who will observe both parties, so that workers and management are satisfied with each other.

Job satisfaction had a different level of measurement between civil servant and private servant. According to [13], a civil servant feels more valued by the society, they are more likely to have higher levels of public service motivation which will contribute to higher level of individual job satisfaction as compared to private servant who are most likely try to meet the company demand most of the time. A different generation also can have a different level of job satisfaction. This is supported by the finding by [9] where she suggested that for a company to hire Gen Y workers, they must be treated differently in terms of their workspace where Gen Y prefers more home based working environment, techno-savvy since Gen Y expect the organization to be equipped with current technology and clear direction by the company as Gen Y demand immediate feedback on their performance. Failing to provide basic needs by Gen $\mathrm{Y}$ will lead to poor job satisfaction and performance among them.

The working environment consists of a good relationship among workers, good relationship between employer and employee, a clean and safe workplace, a comfort workplace and many more will motivate workers to work every day. In [10] supports this finding in their research where they stated that, besides salary, to increase job satisfaction one must also provide a good environment among workers. In their research about voluntary child welfare workers, besides three main factors highlighted which are pays, benefits and supervision, the nature of the job also can propose a good job satisfaction among workers. In $[6,14]$ on the other hand had a different view of working environment. Both papers which are on healthcare and emergency department working area respectively suggested that workers must love their job in order for them to accept their working environment as it is.

Based on all the literature, we decide to narrow down our factors which contributing to the level of job satisfaction which are the productivity, working environment and organization since most of the literatures agree that these are the main factors which will create workers who love their job or not.

\section{Methodology}

This study aims to explore the factors related to job satisfaction specifically in manufacturing industry. Manufacturing industry is one of the major contributors to the development of each country worldwide. In Malaysia, manufacturing contributes $23 \%$ to the economic growth in 2017. In the era of industry revolution 4.0, intense competition requires the management to take into account the level of employee satisfaction in order to create a healthy and safe working environment. This factor is very important because employees are the most important asset in a company. In order to ensure that the achievement of production is maximized, the management should always take measures to improve the welfare and needs of the employees.

Turnover rates and high absenteeism rates have had a great impact on the reputation of a factory, especially factories that turn almost $80 \%$ into human factor. Therefore, this study takes a step towards identifying factors that affect job satisfaction among workers in the $\mathrm{ABC}$ Factory. The ABC Factory is a factory that manufactures wire for several car models. The plant also relies largely on workers to carry out the wiring process according to the required car model. This process cannot be automated because it requires high and accurate research stages.

The $\mathrm{ABC}$ factory has raised concerns in terms of high turnover rates, employee absenteeism and other factors contributing to the workforce. The early stages of this study were conducted to identify factors affecting the level of employee satisfaction. The set of questionnaires was distributed to almost 80 employees covering several departments. The set of questionnaires (Table 1) is divided into 2 parts, the first part involves the respondent background, while the second part includes 4 Likert scale direct questionnaire about the level of job satisfaction.

Fig. 1 presents the conceptual framework on job satisfaction as stated in the above literature.

Table 1: Structure of questionnaire

\begin{tabular}{|c|c|}
\hline Section & Tariable \\
\hline A & Respondents' background \\
\hline B & Job satisfaction \\
\hline
\end{tabular}




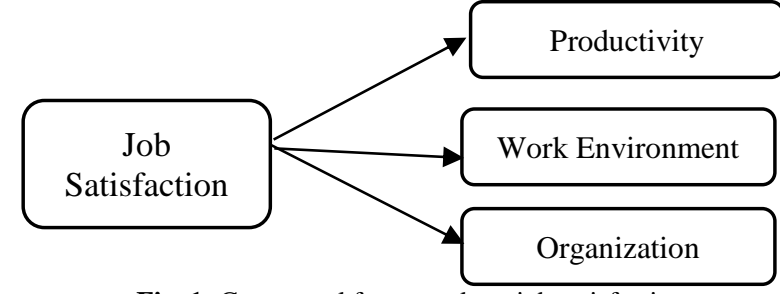

Fig. 1: Conceptual framework on job satisfaction

This study performed two main analyses that are Descriptive Analysis and Exploratory Factor Analysis (EFA) using IBM SPSS Statistics 22 package. Descriptive Analysis is an essential for every research to describe the data into informative way, where the demography data is presented graphically in terms of percentage [45].

Then it followed by Exploratory Factor Analysis (EFA) where the normality assumption should be initially determined. Normality Test is conducted to identify, whether the data follow normal assumption by measuring the skewness values. A common threshold for normality is the value of skewness should lie between 2 and -2 . This test is fundamental to check the data acceptability for performing a parametric analysis (factor analysis) [4-5].

In Exploratory Factor Analysis (EFA), firstly it is looking at the Kaiser-Meyer-Oikin (KMO) value that measure of sampling adequacy for the variables is close to $1.0[4-5,15]$. It indicates that data is suitable for Principal Component Analysis [16]. Similarly, the Bartlett's Test of Sphericity to see the sufficiency correlation items to proceed in the analysis when it is significant at $\mathrm{p}<0.001$, which means that there are some relationships between the items. Since both of the tests were significance, it is suggesting that the data is appropriate to proceed with data reduction procedure to group the items into acceptable components [16]. Then, all 25 items are loaded into respective factor with a minimum factor loading of 0.4 [16-17].

A reliability test is conducted to ensure all factors are accepted as being reliable for the research in order to enhance the accuracy of the assessment and evaluations [16]. The Cronbach's Alpha is used to provide a measure of the internal consistency of a test or scale that is expressed as a number between 0 and 1 [5]. The values more than 0.6 consider reliable as recommended by [18].

\section{Results and Discussion}

\subsection{Descriptive Analysis on Respondent's Background}

Employees opinion regarding to the questionnaires is explained below through various statistical tables. Respondents' background in Table 2 consisted of 35 males and 45 females. Majority of respondents have a working experience from 1 to 3 years $38.8 \%$ (31 respondents), followed by less than 6 months working experience which is $20 \%$ (16 respondents) and more than 5 years $20 \%$ (16 respondents). Others 3-5 years $11.3 \%$ (9 respondents), and 6 months to 1 year $10 \%$ (8 respondents).

Data collection were done from nine positions which are clerks $6.4 \%$ (5 respondents), dandoris 3.8\% (3 respondents), engineers $17.5 \%$ (14 respondents), supervisors $6.3 \%$ (5 respondents), production members $42.5 \%$ (34 respondents), executives $7.5 \%$ (6 respondents), officers $3.8 \%$ (3 respondents), SHOs $1.3 \%$ (1 respondents), and technicians $10 \%$ (8 respondents).

Table 2: Respondents' background

\begin{tabular}{|c|c|c|c|}
\hline Background & Items & Frequency & Percentage \\
\hline Gender & Male & 35 & $43.8 \%$ \\
\cline { 2 - 4 } & Female & 45 & $56.3 \%$ \\
\hline $\begin{array}{c}\text { Working } \\
\text { Experience }\end{array}$ & less than 6 months & 16 & $20 \%$ \\
\hline & 6 months to 1 year & 8 & $10 \%$ \\
\hline & 1 to 3 years & 31 & $38.8 \%$ \\
\hline & 3-5 years & 9 & $11.3 \%$ \\
\hline & more than 5 years & 16 & $20 \%$ \\
\hline
\end{tabular}

\subsection{Normality Test}

This paper consists of three items to identify the level of productivity, work environment and organization towards job satisfaction among the employees of Factory ABC. The result of the normality test is shown in Table 3 . As a result, the skewness statistics for 25 items based on 80 employees' responses. Based on the skewness statistic of each item, it found that all values were fall within the range 2 and -2 . It indicated that the data follows normal assumption and acceptable to proceed with parametric analysis which is an Exploratory Factor Analysis.

Table 3: Normality test

\begin{tabular}{|c|c|c|c|}
\hline Item & Skewness statistic & Item & Skewness Statistic \\
\hline Q1 & 0.185 & Q13 & -0.395 \\
\hline Q2 & 0.316 & Q14 & 0.361 \\
\hline Q3 & -0.535 & Q15 & -0.393 \\
\hline Q4 & 1.014 & Q16 & 0.647 \\
\hline Q5 & -0.928 & Q17 & 0.069 \\
\hline Q6 & 0.540 & Q18 & 0.517 \\
\hline Q7 & -0.641 & Q19 & 0.050 \\
\hline Q8 & 0.134 & Q20 & 0.316 \\
\hline Q9 & 0.197 & Q21 & 1.335 \\
\hline Q10 & -0.284 & Q22 & 0.349 \\
\hline Q11 & -0.855 & Q23 & 0.316 \\
\hline Q12 & 1.149 & Q24 & 0.842 \\
\hline & & Q25 & 0.327 \\
\hline
\end{tabular}

\subsection{Exploratory Factor Analysis}

Exploratory factor analysis is used for reducing the number of variables to a smaller set of underlying summary variable or component. This method is one of a statistical method to uncover the underlying structure of a relatively large set of variables [19]. In order to present the adequacy of the analysis, Kaiser-Meyer-Olkin (KMO) coefficient is calculated and expected to be close to 1 . In this research, the KMO result is 0.642 and meet the requirement for the adequacy condition. In addition, for the Bartlett's test of Sphericity showed a significant value where the Chi-Square value was 798.569 with p-value less than 0.001 . The result indicates the sufficient correlation between all pairs of items. Hence, the number of data is appropriate in this analysis.

Table 4: Result of KMO and Bartlett's Test

\begin{tabular}{|c|c|}
\hline \multicolumn{2}{|c|}{ Table 4: Result of KMO and Bartlett's Test } \\
\hline Kaiser-Meyer-Olkin & 0.642 \\
Measure of Sampling Adequacy & \\
\hline Bartlett's Test of Sphericity & 798.569 \\
Approximation Chi-Square & 300 \\
Degree of freedom & 0.000 \\
p-value & \\
\hline
\end{tabular}

Table 5: Component extraction

\begin{tabular}{|c|c|c|c|c|c|}
\hline C1 & FL & C2 & FL & C3 & FL \\
\hline Q4 & 0.655 & Q1 & 0.408 & Q3 & 0.522 \\
\hline Q6 & 0.524 & Q5 & 0.627 & Q12 & 0.799 \\
\hline Q17 & 0.653 & Q7 & 0.549 & Q13 & 0.680 \\
\hline Q18 & 0.435 & Q8 & 0.594 & Q14 & 0.551 \\
\hline Q19 & 0.757 & Q9 & 0.658 & Q15 & 0.487 \\
\hline Q20 & 0.672 & Q10 & 0.517 & Q16 & 0.500 \\
\hline Q24 & 0.534 & Q11 & 0.456 & Q21 & 0.465 \\
\hline Q25 & 0.593 & Q22 & 0.499 & & \\
\hline & & Q23 & 0.622 & & \\
\hline
\end{tabular}

$* \mathrm{C}=$ component

$* \mathrm{FL}=$ factor loading

In this research, the loading factor were set at the minimum level with 0.4. There are eight items are loaded into Component 1 (Productivity), nine items are assigned into Component 2 (Work Environment) and finally, seven items are assigned into Component 3 (Productivity) as summarized in Table 4. 


\subsection{Reliability Test}

After performing an exploratory factor analysis, the reliability test was conducted in order to examine the reliability for each component by computing a Cronbach's Alpha value. These values must be more than 0.6 , so that we can conclude the items are loaded to the reliable components. Table 6 illustrated the results of Cronbach's Alpha for each component. As a result, all the Cronbach's Alpha values are more than 0.6 which indicated that those components extracted have a reliable measure of consistency among the 80 employees.

Table 6: Result of reliability test

\begin{tabular}{|c|c|}
\hline Component & Cronbach's Alpha \\
\hline 1 & 0.795 \\
\hline 2 & 0.758 \\
\hline 3 & 0.697 \\
\hline
\end{tabular}

\section{Conclusion}

As a conclusion based on the factor analysis, this research found that there are three components factors related to job satisfaction at ABC factory. The set of questionnaires (Q1 to Q25) could be classify according to the relevance component $(\mathrm{C} 1$ = productivity; $\mathrm{C} 2$ = work environment; $\mathrm{C} 3$ = organization) .

\section{Acknowledgement}

The authors would like to thank the Faculty of Computer and Mathematical Sciences, Universiti Teknologi MARA, Tapah Campus for the support and facilities which smoothen the research activities. The authors' special appreciation goes to Raja Nur Zalikha Raja Akram from the ABC factory who has given very good assistance and support in the research. Also, thank you to all the staff in the $\mathrm{ABC}$ factory who have supported our work and participated in the survey, and for whoever who has involved and contributed directly or indirectly in this research.

\section{References}

[1] Spector P (1997), Job satisfaction: Application, assessment, causes and consequences. Sage Publications.

[2] Abdul R (2015), Impact of working environment on job satisfaction. Procedia Economics and Finance 23, 717-725.

[3] Elfenbein HA \& O'Reilly CA (2007), Fitting in: The effects of relational demography and person-culture fit on group process and performance. Group and Organization Management 32, 109-142.

[4] Abdul LS, Omar MS, Bidin YH \& Awang Z (2012), Environmenta problems and quality of life: Situational factor as a predictor of recycling behaviour. Procedia - Social and Behavioral Sciences 35, 682-688.

[5] Abdul LS, Omar MS, Bidin YH \& Awang Z (2013), Analyzing the effect of situational factor on recycling behavior in determining the quality of life. Journal of Asian Behavioral Studies 3(6), 11-17.

[6] Suárez M, Asenjo M \& Sánchez M (2017), Job satisfaction among emergency department staff. Australasian Emergency Nursing Journal 20, 31-36.

[7] Oded R, Miki M \& Ro'i Z (2017), The effect of economic cycles on job satisfaction in a two-sector economy. Journal of Economic Behavior and Organization 138, 1-9.

[8] Kum FY, Hui SL, Qingji Z \& Yiik DW (2018), Determinants of job satisfaction and performance of seafarers. Transportation Research Part A: Policy and Practice 110, 1-12.

[9] Normala D (2016), Determinants of job satisfaction: How satisfied are the new generation employees in Malaysia? Procedia - Social and Behavioral Sciences 219, 208-213.

[10] Kent WJ, Ye L \& Thomas S (2017), Entrepreneurs innovation bringing job satisfaction, work-family balance, and life satisfaction: In China and around the world. International Journal of Innovation Studies 1, 193-206.

[11] Sabine P \& Maura G (2017), The role of supervisor emotional support on individual job satisfaction: A multilevel analysis. Applied Nursing Research 33, 61-66.
[12] Katharina K, Miet M \& Meike W (2018), The role of fairtrade certification for wages and job satisfaction of plantation workers. World Development 102, 195-212.

[13] Brent SS, John CP, Evan B \& Jeanette T (2017), Job satisfaction in Cascadia: A comparison of British Columbia, Oregon, and Washington civil servants. Social Science Journal 54, 379-388.

[14] Ayodotun SI, Hezekiah OF, Oyebisi MI, Odunayo PS, Maxwell AO, Taiye TB, Augusta BA \& Fred P (2018), Workforce diversity among public healthcare workers in Nigeria: Implications on job satisfaction and organizational commitment. Data in Brief 18, 1047-1053.

[15] Kaiser HF (1974), An index of factorial simplicity. Psychometrika 39, 31-36.

[16] Habidin NF \& Yusof SM (2013), Critical success factors of Lean Six Sigma for the Malaysian automotive industry. International Journal of Lean Six Sigma 4, 60-82.

[17] Hatcher L (1994), A step-by-step approach to using the SAS system for factor analysis and structural equation modeling. SAS Institute Inc.

[18] Nunnally JC (1978), Psychometric theory. McGraw-Hill.

[19] Norris M, \& Lecavalier L (2010), Evaluating the use of exploratory factor analysis in developmental disability psychological research. Journal of Autism and Developmental Disorders 40, 8-20. 